\title{
Militarização e normalização capitalista: a presença das UPPs nas favelas cariocas sob a perspectiva de Marielle Franco
}

Militarization and capitalist normalization: the presence of UPPs in the Rio de Janeiro's slums through the analysis of Marielle Franco

\section{Rodrigo de Abreu Pinto \\ rdeabreupinto@gmail.com}

Graduando de Direito - PUC-Rio

\begin{abstract}
Resumo
Ao partir da análise da dissertação de Marielle Franco sobre as Unidades de Polícia Pacificadora (UPPs), este artigo aprofunda os pontos de vista trabalhados pela autora, sem deixar de desdobrar outros caminhos inspirados pelo próprio texto, conciliando a perspectiva de Marielle sobre a política de segurança pública do Rio de Janeiro com a fase atual do desenvolvimento capitalista.

Palavras-chave: Marielle Franco; UPP; segurança pública; favela; capitalismo.
\end{abstract}

\begin{abstract}
Starting from the analysis of Marielle Franco's dissertation about Pacifier Police Units (UPPs), the author's points of view are deepened, while still unfolding other paths inspired by the text itself, reconciling Marielle's perspective about politics of public security in Rio de Janeiro with the current phase of capitalist development.
\end{abstract}

Keywords: Marielle Franco; UPP; public security; slum; capitalism. 


\section{Introdução}

Os laços estreitos de Marielle e a experiência social carioca são conhecidos. Moradora da Maré, junto às populações marginalizadas cerrou fileira e punho - jamais os olhos. Seja como parlamentar - quando atuou na Câmara Municipal contra a violência policial, a precariedade dos serviços públicos e todo rol de pautas sociais que urgem transformar a vida dos mais pobres - seja como intelectual - ao produzir a dissertação de mestrado sobre a implementação das Unidades de Polícia Pacificadora (UPPs) nas favelas do Rio de Janeiro, além da coluna no Mídia Ninja, em que discutiu o apartheid social em voga na cidade em que nasceu e morreu brutalmente assassinada.

No encalço dos rastros que Marielle deixou, resiste a força de quem segue vivo só porque os segue. Discuto a seguir a produção teórica de Marielle, em especial o estudo sobre o projeto da UPP, tomando a liberdade de alimentar e desdobrar questões que encontrei a ponto de germinar na obra da autora.

\section{Novo tempo dos morros}

UPP - Redução da favela a três letras, dissertação de mestrado de Marielle Franco, investiga o projeto que nomeia a peça e que centralizou as ações do Estado sobre as favelas cariocas em anos recentes. O subtítulo, "Uma análise da política de segurança pública do estado do Rio de Janeiro", explicita a sua perspectiva de análise: a vereadora quer saber qual a novidade introduzida pelo projeto das UPPs na política de segurança pública do Rio de Janeiro. Para tanto, Marielle não parte de uma recusa absoluta do projeto. Interessa-lhe, sobretudo, investigar a distância entre o conceito e a implementação, o desenho original e o resultado final, trazendo à baila as reflexões de Loïc Wacquant sobre a atuação do poder estatal em pleno acordo com as necessidades do capitalismo em seu atual estado de acumulação.

Marielle destaca como a concepção original das Unidades apresentava "um novo modelo de Segurança Pública e de policiamento que promove a aproximação entre a população e a polícia, aliada ao fortalecimento de políticas sociais nas comunidades" (FRANCO, 2014, p.64). Para solucionar o problema da violência nos morros, o Estado finalmente compreendeu que não bastava uma intervenção armada que reprimisse o domínio das facções, mas mantivesse as demais esferas de sociabilidade em estado de inanição. Por isso, em lugar da política segurança pública privilegiar a militarização, o Estado assumiria o desafio de "constituir políticas públicas 
PINTO, Rodrigo Abreu. Militarização e normatização capitalista: a presença das UPPs nas favelas cariocas sob a perspectiva de Marielle Franco.

voltadas para dialogar com a população e ampliar serviços e equipamentos do Estado para elevar a qualidade de vida dos moradores das favelas" (FRANCO, 2014, p.125).

Sendo assim, as UPPs significariam uma alteração qualitativa na atuação secular do Estado brasileiro, uma vez rompido o pendor autoritário em tratar a questão social unicamente como "caso de polícia". Para além da "pacificação", era questão de reestabelecer o sentido comunitário das favelas por meio do resgate da soberania contra as facções e, não menos importante, da relação renovada entre Estado e população.

Naquela altura, o exemplo a ser seguido era Medellín, cidade colombiana em que persistiam problemas semelhantes quanto à violência de grupos armados e a baixa qualidade dos serviços públicos. A região, então, foi palco de uma grande ação do Estado, que "foi além da retomada dos territórios antes sob influência do poder paralelo, propondo medidas efetivas de assistência e aproximação com a população" (FRANCO, 2014, p.64). Se é certo que os tigurios (as favelas colombianas) foram alvos de ações propriamente militares contra o narcotráfico, Marielle ressalta os outros dois braços da operação.

Em primeiro lugar, a "reforma na corporação policial" que promoveu a "exclusão de dois mil agentes envolvidos em assassinatos e favorecimento ao tráfico" (FRANCO, 2014, p.69). Essa ação esterilizou a polícia antes de engajá-la na operação, momento em que foi dividida em dois grupos: "uma unidade especializada para combate urbano" e uma outra perita em "segurança cidadã”, cada qual preparada para uma etapa do processo civilizatório. Em segundo lugar, os tigurios receberam obras públicas colossais que sinalizavam a permanência do Estado e encheram as periferias de Medellín com bibliotecas, cinemas, centros de informática, postos de saúde, delegacias e sistemas de transporte adequados às condições locais.

Os resultados foram impressionantes. Em 2002, 6.500 pessoas foram assassinadas em Medellín, o que equivale a 381 homicídios por 100 mil moradores - taxa que lhe rendeu o título de cidade mais violenta do mundo. Já em 2007, o índice foi reduzido para 26 assassinatos por 100 mil habitantes! Foi nesse ano que Sérgio Cabral, então governador do Rio de Janeiro, visitou a cidade e elogiou a diminuição da criminalidade através de maciços investimentos sociais. Segundo Cabral, "a experiência colombiana mostra que o enfrentamento do crime com todas as forças é a única saída para entrar nas áreas ocupadas por criminosos armados" (PINHEIRO, 2007).

A UPP inaugural surgiria no morro de Santa Marta já no ano seguinte (2008). Dali em diante, mais 37 Unidades seriam criadas. Tomando o caso de Medellín como exemplo, conforme explica Marielle, o processo de ocupação era dividido em quatro etapas. 
PINTO, Rodrigo Abreu. Militarização e normatização capitalista: a presença das UPPs nas favelas cariocas sob a perspectiva de Marielle Franco.

A primeira, denominada intervenção tática, consistia em ocupar com tropas especializadas (Bope, BPChoque e Exército) e assumir o controle militar do território. Em seguida, a estabilização, momento em que o poder público assenta o domínio e inicia a construção das políticas sociais. No terceiro estágio, da implementação, a tropa armada é substituída pela polícia de proximidade, também conhecida como polícia comunitária, a fim de estabelecer o elo entre a polícia, a população e os novos serviços públicos. Por fím, a última etapa era a de monitoramento, em que se dava a análise contínua do andamento das operações.

Sendo assim, estão presentes as três linhas de força da experiência colombiana: ocupação militar, polícia comunitária e políticas sociais. Marielle, no entanto, insistirá que os dois últimos estágios, justamente os que conformam a novidade das UPPs, jamais ocorreram. Ao menos não como deveriam, ou seja, efetivos na prática e não apenas na propaganda governamental.

\section{Estado de emergência permanente}

Para que o efeito deletério e intimidatório das forças policiais não atrapalhasse o processo, a intervenção armada não deveria tardar em ceder lugar às políticas comunitárias. No entanto, a "metáfora da guerra" (LEITE, 2012) - bem expressa nas bandanas de caveira, nas bandeiras fincadas no terreno e em todo simbolismo de guerra que sobe ao morro junto aos militares converteu-se em modus operandi permanente das ocupações.

Nas palavras da vereadora, em vez de "criar instrumentos de redução progressiva do uso da arma e da quantidade de efetivos para sustentar tais ocupações” (FRANCO, 2014, p.47), as abordagens ostensivas, os mandatos coletivos e as prisões cautelares se tornaram a regra. Foram ficando mais evidentes "as contradições de um modelo autoproclamado pacificador, mas que na essência é militarizado" (FRANCO, 2014, p.95). A única diferença em relação ao modelo anterior é que as incursões policiais foram substituídas pela ocupação permanente, muito embora isso não seja suficiente para identificar uma ruptura no que diz respeito à relação do Estado com a favela.

Este maligno cenário de administração armada da vida social contrariou a promessa de reconquista da soberania dos territórios. Antes, o tráfico. Agora, a polícia. Para quem achar ruim, basta lembrar o princípio do mal menor, pelo qual a opressão da polícia seria preferível à do tráfico. A questão, no entanto, é que ambas situações interrompem a organização e imaginação política dos moradores, privando-os do sentimento comunitário de integrarem um povo, no sentido solidário do termo, e não uma população controlada. 
PINTO, Rodrigo Abreu. Militarização e normatização capitalista: a presença das UPPs nas favelas cariocas sob a perspectiva de Marielle Franco.

Sobre as UPPs, Marcia Leite reconheceu que as forças policiais atuaram para "usurpar a representação de suas organizações de base (especialmente, mas não só, as associações de moradores) e assim se converter em mediação política necessária entre moradores de favela e Estado" (2014, p.18). Uma vez a Unidade já instalada, a polícia não cessa de suprimir (não raro com uso da violência) os espaços de diálogo dos moradores, o que impede os favelados de elaborarem os próprios regulamentos e normas de convivência social, para não falar da proibição de práticas culturais como o baile funk. De modo complementar, os despachos quanto aos usos da favela são produzidos nos batalhões da polícia e gabinetes dos políticos, quase sempre desvirtuados dos problemáticas reais. Não se realiza, portanto, "a cidadania ativa contra a regulação da força", e um dos alicerces das UPPs cai por terra.

A militarização permanente, que equivoca o princípio da polícia comunitária, termina por conformar uma "nova hierarquização das prioridades públicas aplicadas às favelas" (FRANCO, 2014, p.18). Em outras palavras: as políticas públicas de cunho social são relegadas ao episódico, enquanto a gerência armada se torna estrutural. Se não bastassem os gastos exorbitantes das ações militares, responsáveis por sugar boa parte dos recursos do Estado, a inversão de prioridades acontece na base mesma de justificação ideológica das UPPs.

Isso porque revelou-se muito mais valioso para o Estado, em termos de capital simbólico e político, "reafirmar a autoridade do Estado e a vontade reencontrada das elites políticas de enfatizar e impor a fronteira sagrada entre os cidadãos de bens e as categorias desviantes" (WACQUANT, 2003, p.16), como escreve Wacquant, autor que inspira a pesquisa de Marielle. Por via dessa lógica, tornou-se preciso isolar o território e sustentar a existência insone do "inimigo", mesmo que os traficantes sejam, na descrição de Paulo Arantes, "somente o elo mais fraco do circuito internacional do comércio de drogas e armamentos, os mesmos que nunca cogitaram enfrentar o Estado para valer" (2014, p.369). A meta é a manutenção do estado de emergência permanente, pelo qual se exige um aparato policial ostensivo cuja finalidade é ser visto e exibido. A atenção pragmática aos desprovimentos das favelas é substituída pelo culto do desempenho performático contra o "mal".

Em nome da blindagem às críticas, instalou-se um pêndulo perverso em que, à medida que surgiam denúncias de violações de direitos humanos pelas forças policiais, o governo do estado dobrava a aposta em "produzir uma impressão, na população, de que estava em jogo a defesa de todos". Ao fim e ao cabo, prevalecia a apelação ideológica pela paz, o que acirrava as ações violentas e veladas contra os favelados. Ao mesmo tempo que os políticos podiam 
PINTO, Rodrigo Abreu. Militarização e normatização capitalista: a presença das UPPs nas favelas cariocas sob a perspectiva de Marielle Franco.

“exibir-se no ato de entrega de um serviço essencial aos cidadãos trabalhadores: a proteção viril contra os bandidos de rua" (WACQUANT, 2003, p.18), como bem anotou Wacquant.

Não por outro motivo, o discurso contra a violência garantiu que Sérgio Cabral ganhasse as eleições de 2010 ainda no primeiro turno, com 66\% dos votos, tornando-se o primeiro governador do Rio a conquistar a reeleição em mais de 60 anos. Neste cenário em que o Estado age violentamente e ainda assim (ou melhor, por isso mesmo) ganha eleição, não é difícil imaginar, como indica Marielle, "que as políticas públicas sociais chegam, no mínimo, em segundo plano, e em determinadas regiões nem chegam" (2014, p.57). Logo que retornou da viagem a Medellín, ainda em 2007, Sérgio Cabral anunciou o "PAC das Favelas", em que prometia uma série de obras públicas nos morros cariocas. Mais de dez anos depois, com algumas exceções como o teleférico no Complexo de Alemão (realmente concluído e quase igual ao de Medellín), a maioria das obras não foi concluída ou sequer saiu do papel.

Analisando a obra de Marielle, pode-se dizer que a autora, ao menos inicialmente, acreditou que a implementação de políticas públicas após a pacificação, como a construção de infraestrutura urbana e a efetivação de serviços públicos, seria capaz de interromper a sina das ocupações estritamente securitárias e configurar um Estado disposto a valorizar a favela. Entretanto, não demorou muito para que a vereadora constatasse o contrário: assim como a polícia comunitária jamais substituiu a militarizada, a UPP não encarnaria a presença do Estado Social naquele espaço.

Para além dos problemas financeiros e ideológicos já aqui citados, a autora destaca uma série de problemas administrativos, relativos ao necessário envolvimento dos vários órgãos que compõem as pastas das políticas sociais. Segundo a avaliação de Marielle, o governo falhou na “articulação entre as diversas instituições estatais para proporcionar aos moradores, com a agilidade e qualidade esperadas, os equipamentos e serviços públicos prometidos". A consequência não foi outra, senão que "um conjunto de políticas públicas fica, nesse sentido, submerso e não aparece na ação do Estado (ou aparece de forma tímida e secundária), reforçando a ação policial como a questão central" (FRANCO, 2014, p.47).

Seguindo mais de perto a leitura de Wacquant, esta inaptidão do Estado em executar o projeto das UPPs não deve ser lida somente como um defeito da má implementação do traçado original. Na verdade, a atuação do Estado nas favelas, ao não abrir mão do enquadramento penal da população favelada, é condizente com as exigências do capitalismo. Como também viu Marielle, estamos diante de "uma iniciativa ideológica que responde às necessidades do momento" (FRANCO, 2014, p.15). 
PINTO, Rodrigo Abreu. Militarização e normatização capitalista: a presença das UPPs nas favelas cariocas sob a perspectiva de Marielle Franco.

Para decifrar tais urgências, Wacquant insiste que o estágio atual de acumulação está marcado pela superação da sociedade do trabalho rumo a era do pós-trabalho. Para isso, somamse fatores como a eliminação do trabalho vivo da produção através da tecnologização generalizada; a concentração das riquezas nos canais de valorização financeira; e outros efeitos da globalização como o deslocamento das cadeias produtivas para a Ásia.

A partir de então, o comportamento do Estado cumpre uma dupla função. Por um lado, "o encarceramento serve para neutralizar e estocar fisicamente as frações excedentes" para que a massa de desempregados não perturbe o ambiente social. Por outro, a militarização intensifica a pressão sobre o tráfico de drogas e assim acarreta "a elevação do custo das estratégias de escape" contra aqueles que não quiserem se adequar aos empregos remanescentes (em sua maioria precários e mal remunerados) - o que serve para manter elevado o excedente de mão de obra, essencial para a manutenção dos salários em níveis rebaixados. Para Wacquant, portanto, a simbiose entre Estado Penal e capitalismo não é acessória, mas estrutural, já que o segundo não se sustenta sem que o primeiro regule continuamente os excluídos do sistema.

\section{"É a hora de aproveitar o momento para fazermos um banho de loja"}

“Direitos fundamentais não estão à venda nas lojas". Este é o título de um dos artigos de Marielle para a Mídia Ninja, em que a vereadora desdobra uma das conclusões da sua tese. Se é verdade que o estatuto militarizado das Unidades não rompeu com os padrões históricos de atuação do Estado brasileiro, não é menos verdade que a ocupação das favelas viabilizou um modelo de cidadania. Desta vez, para além do estado de bem-estar social, uma cidadania mediada pelo mercado. Esta é a verdadeira novidade das UPPs, que Marielle sugere, mas não aprofunda, trabalho ao qual se dedicaram outros sociólogos cariocas que agora acompanhamos.

Normalmente, a relação entre UPP e mercado é analisada pelo prisma externo. A própria Marielle destaca "um aumento de até $400 \%$ nos preços de imóveis no entorno das favelas ocupadas pelas UPPs" (2014, p.85), o que provocou enormes excrescências no mercado imobiliário e a manchete que "morar no Rio é mais caro que em Miami”. Ao lado disso, as Unidades se justificavam pela sensação de segurança para os futuros megaeventos que então se aproximavam (caso da Copa do Mundo e Olimpíadas, mas não apenas esses).

Não obstante, é quando investigamos as transformações nos mercados internos - ou seja, no interior das próprias favelas _ que as análises trazem dados mais interessante e pouco difundidos. De acordo com as pesquisas desenvolvidas nas comunidades, as novidades estão 
PINTO, Rodrigo Abreu. Militarização e normatização capitalista: a presença das UPPs nas favelas cariocas sob a perspectiva de Marielle Franco.

representadas em dois processos que ocorrem na esteira das ocupações: a ampliação do mercado consumidor interno e a promoção do espírito empreendedor dos moradores.

\section{Não há contradição entre consumo e favela}

A ampliação do mercado consumidor interno corresponde à exploração da favela como um nicho de mercado, a "entrada dos grandes negócios na favela" (FRANCO, 2014, p.80). Para apreender os seus reais efeitos, deve-se levar em conta que, historicamente, as favelas foram marcadas por constituírem um circuito econômico inferior, expresso no "heterogêneo e fluido leque de atividades de pequena dimensão e ínfimo suporte tecnológico, sem mediação estatal, com predomínio da informalidade, utilização intensiva de mão-de obra e configuração espacial local" (BOTELHO, 2013, p.178), conforme a precisa descrição de Maurilio Lima Botelho. Dito de outro modo: trata-se de um mercado voltado para a população pobre cuja carência material não pode ser suprida pelo varejo formal do centro capitalista, em razão, claro, dos preços elevados das mercadorias.

No circuito econômico superior, por sua vez, predominam os empreendimentos com escala industrial, padrões tecnológicos sofisticados, apoio estatal e circulação internacional. Ora, à medida que o circuito superior, concentrado nas zonas centrais e abastadas do Rio de Janeiro, deparou-se com limites para a sua expansão (o que induziria uma tendência decrescente da taxa de lucros), os mais diversos segmentos empresarias enxergaram um potencial de mercado nos circuitos inferiores.

As favelas, enfim, revelaram-se como um denso mercado consumidor, muito embora à parte do circuito comercial das grandes marcas, o que as tornava uma verdadeira oportunidade de investimentos. Nesse sentido, no que diz respeito à missão das UPPs, coube-lhes estender as garantias das empresas privadas nos territórios ocupados, iniciando uma nova fase de espraiamento do capitalismo pelas favelas. Afinal, se os serviços públicos não dão conta da comunidade, a cidadania será materializada via consumo.

O que acontece a partir de então? As fontes piratas e informais, que historicamente serviam os moradores, são trocadas pelos serviços “oficiais". Com efeito, o primeiro de todos é o serviço de TV a cabo - como disse um morador às pesquisadoras Livia De Tommasi e Dafne Velazco, "a Net sobe o morro já no carro da polícia de ocupação" (TOMMASI \& VELAZCO, 2013, p.28). Em seguida, os demais serviços essenciais são "regularizados” - luz, água, gás, telefone. Até que, em pouco tempo, todo um circuito comercial vinga no território, como listou 
PINTO, Rodrigo Abreu. Militarização e normatização capitalista: a presença das UPPs nas favelas cariocas sob a perspectiva de Marielle Franco.

Botelho: "aviários, armazéns, açougues, bares, restaurantes, cabeleireiros, fliperamas, lan houses, lojas de penhores, agências imobiliárias e mesmo bancos". É toda uma gama de atividades que se instalam no espaço urbano da favela para aproveitar as oportunidades de negócio (2013).

À primeira vista, a multiplicidade da coisa parece atrativa, mas resta que investiguemos as consequências relativas aos moradores locais. O que pensar, por exemplo, dos antigos comerciantes que são obrigados a regularizarem o empreendimento via abertura de CNPJ? O processo de regularizar o negócio, de acordo com as exigências da prefeitura, envolve custos e paciência, o que não pode levar muito tempo, já que os fiscais também sobem tão rápido quanto a Net. Na leitura de Marielle, o processo de legalização “pode trazer prejuízo para o conjunto dos moradores e ainda gerar perdas - devido a legalização, impostos e manutenção - de empreendimentos locais que foram criados antes da chegada das próprias UPPs" (2014, p.82).

Para os moradores, de modo geral, o principal efeito é o aumento do custo de vida, o que sequer acompanha a melhoria na qualidade dos serviços. A TV a cabo, por exemplo, não somente se torna mais cara, mas o "assinante" passa a ter acesso a uma quantidade mais limitada de canais do que tinha. Já o serviço de luz, que antes sequer integrava o orçamento das famílias, torna-se parte importante dos gastos, sobretudo porque o preço da luz praticamente não se diferencia do cobrado na Zona Sul, muito embora nessa última o serviço seja bem melhor.

\section{A subjetividade empreendedora nas favelas}

Para além da renovação do mercado consumidor, a instalação das UPPs desencadeou o advento do empreendedorismo como modalidade subjetiva dos moradores das favelas. No mesmo compasso em que o Estado recuava de suas tarefas históricas, os sujeitos eram chamados a assumirem as rédeas do próprio destino enquanto empreendedores, o que se dava através da maximização da "livre-iniciativa" como norma fundamental de ação. Para tanto, bastava acessarem algum dos cursos oferecidos pelo Sebrae nos próprios morros, em sua maioria voltados à formação de empreendedores individuais (EI), e então aproveitarem as linhas de microcrédito oferecidas aos "moradores-empreendedores", subsidiadas pelo governo. Em lugar dos serviços públicos, as garantias de condições mínimas de vida dependeriam do sucesso e sorte no mercado, muito embora nesse cassino a quantidade de perdedores supere os vencedores. 
PINTO, Rodrigo Abreu. Militarização e normatização capitalista: a presença das UPPs nas favelas cariocas sob a perspectiva de Marielle Franco.

Estendendo o fio das ideias de Wacquant, o estímulo ao autoempreendedorismo é extremamente funcional às demandas do capitalismo contemporâneo. Por um lado, o empreendedorismo dos pobres é a contraparte dialética da diminuição do trabalho assalariado, antigo modo de inclusão do trabalhador, já que significa um meio termo entre o trabalho formal e o desemprego, o que evita uma massa indesejada de desempregados e os altos custos do Estado com seguro-desemprego. Como bem disse Paulo Arantes, "o empreendedorismo dos pobres não é nenhuma esquina da história nacional, mas uma saída de emergência para o colapso da sociedade salarial no Brasil e no mundo" (2014, p.375).

Por outro lado, o empreendedorismo também desmobiliza os moradores, uma vez que o espírito de comunidade, tão preconizado por Marielle, é debilitado pelas novas polarizações entre os moradores - seja pela concorrência entre os novos microempresários, seja pela diferença entre quem ascendeu socialmente e a maioria que não fez o negócio girar e ficou cheia de dívidas. De agora em diante, o sucesso - compreendido como resultado da autopromoção, esforço individual, flexibilidade em correr riscos - segmenta os moradores das favelas assim como o tráfico fazia. Ao mesmo tempo, desobriga o Estado de construir um sólido sistema de seguridade social - afinal, assim como o sucesso, o fracasso também é responsabilidade do indivíduo, e não adianta mais culpar as deficiências estruturais da sociedade.

\section{UPP e normalização capitalista}

Este trabalho consistiu não em escrever sobre Marielle, mas a partir dela, assumindo como fio condutor a análise que a vereadora e outros autores paralelos realizaram sobre a inserção das UPPs no contexto mais geral da segurança pública e do capitalismo contemporâneo. Para isso, foi questão importante aprofundar matérias que já estavam presentes na dissertação de Marielle, assim como desenvolver outras problemáticas que estavam em latência, principalmente a expansão do mercado de consumo e da ideologia do empreendedorismo nas favelas.

Lançamos mão das reflexões de Wacquant (principal referência da autora) para discutir a funcionalidade da militarização das favelas e da penalização daquelas frações excedentes dos favelados. Além dos sociólogos cariocas dedicados à experiência social da cidade, como Maurilio Lima Botelho, Livia Tomassi, Dafne Velazco e Paulo Arantes, que somam esforços para apreender a normalização capitalista das favelas. Frisamos, no entanto, que várias questões importantes não foram desenvolvidas, como a relação das UPPs com as milícias, as 
PINTO, Rodrigo Abreu. Militarização e normatização capitalista: a presença das UPPs nas favelas cariocas sob a perspectiva de Marielle Franco.

diferenças entre as Unidades dos diferentes morros, o desmonte do programa em tempos recentes. Esperamos que possamos desenvolvê-las no futuro.

À guisa de conclusão, reconhecemos que o projeto original das UPPs não foi levado a cabo, já que nem polícia comunitária nem o Estado Social fincaram raízes nos locais, ao contrário da militarização permanente que transformou a ocupação numa verdadeira administração armada da vida social. A despeito do suposto fracasso, o resultado final não difere do comportamento secular do Estado brasileiro em relação às populações mais pobres, conformando a cada momento a violência tupiniquim com as prerrogativas da acumulação capitalista.

Desta vez, a novidade diz respeito à inserção das favelas no circuito econômico superior, em que predomina o consumo atendido pelas grandes marcas e serviços. Os objetivos socialdemocratas foram transpostos do Estado ao mercado, fomentando um novo modelo de cidadania mediado pelo consumo e o autoempreendedorismo. Como vimos, o principal resultado não foi a "integração", mas a desmobilização dos moradores e da própria capacidade de crítica ao capitalismo, já que as responsabilidades foram reduzidas ao sujeito individual.

Do ponto de vista da acumulação capitalista, as UPPs deram certo justamente porque deram errado, uma vez que sua falha atualizou a supremacia dos mercados na periferia do capitalismo. O mercado, e não o Estado, como regulador por excelência, sem esquecer do rastro de pessoas presas ou mortas que não chegaram a tempo para a festa do consumo. 


\section{Referências bibliográficas}

ARANTES, Paulo. Novo Tempo do Mundo. São Paulo: Boitempo, 2014.

BOTELHO, Maurilio Lima. Crise urbana no Rio de Janeiro: favelização e empreendedorismo dos pobres. In: BRITO, Felipe; OLIVEIRA, Pedro Paulo (orgs.). Até o último homem. São Paulo: Boitempo, 2013.

BRITO, Felipe. OLIVEIRA, Pedro Paulo (orgs.). Até o último homem. São Paulo: Boitempo, 2013.

FRANCO, Marielle. UPP - A Redução da Favela a Três Letras: uma análise da Política de Segurança Pública do Estado do Rio de Janeiro. Dissertação (Mestrado em Administração) Faculdade de Administração e Ciências Contábeis, Universidade Federal Fluminense. Rio de Janeiro. $2014 . \quad$ Disponível em: https://app.uff.br/riuff/bitstream/1/2166/1/Marielle\%20Franco.pdf. Acesso em: 18 abr 2019.

Direitos fundamentais não estão à venda nas lojas. Mídia Ninja, 2 de outubro 2017. Disponível em: http://midianinja.org/?post_type=post\&p=6379. Acesso em: 18 abr 2019.

LEITE, Marcia Pereira. Assim na terra como no céu: entrelaçamento entre religião e política na mediação de conflitos urbanos no movimento de mães de vítimas de violência. Congresso Luso-AfroBrasileiro de Ciências Sociais, VIII, 2004. Coimbra: Universidade de Coimbra, Centro de Estudos Sociais, 2004.

Da "metáfora da guerra" ao projeto de "pacificação": favelas e políticas de segurança pública no Rio de Janeiro. Revista Brasileira de Segurança Pública. v.6, n.2, p.374-89, 2012.

PINHEIRO, Daniela. Mano Dura e Obras Públicas. Revista Piauí. Novembro de 2007. Disponível em: https://piaui.folha.uol.com.br/materia/mano-dura-e-obras-publicas/. Acesso em: 18 abr 2019.

TOMASSI, Livia de; VELAZCO; Dafne. A produção de um novo regime discursivo sobre as favelas cariocas e as muitas faces do empreendedorismo de base comunitária. Revista do Instituto de Estudos Brasileiros, n.56, p.15-42, 2013.

WACQUANT, Loic. Punir os pobres: a nova gestão da miséria nos EUA. Trad. Sérgio Lamarão. Rio de Janeiro: Revan, 2003. 